\title{
Evaluation of oral health status and salivary flow rate in obese patients after bariatric surgery
}

\author{
Juliane A. Marsicano ${ }^{1}$ \\ Arsenio Sales-Peres ${ }^{1}$ \\ Reginaldo Ceneviva ${ }^{2}$ \\ Silvia H. de C. Sales-Peres ${ }^{1}$
}

\begin{abstract}
Objectives: The aim of this study was to identify the prevalence of dental caries, periodontal diseases and tooth wear in bariatric patients, and relate the oral health conditions to saliva flow.

Methods: Fifty-two patients who had undergone bariatric surgery (Roux-en-Y gastric bypass) and 50 severely obese patients indicated for bariatric surgery were submitted to clinical examinations with regard to dental caries (DMFT index), periodontal condition (CPI index), dental wear (DWI index - Dental wear index) and saliva flow. The data were statistically analyzed by the Student's-t, MannWhitney, Spearman Correlation and Chi-square $\left(\chi^{2}\right)$ tests at $5 \%$ significance level.

Results: The DMFT index was $16.11 \pm 5.19$ in the surgical group and $16.06 \pm 6.29$ in the control group $(P>$.05). The mean CPI was $3.05 \pm 0.84$ for the operated group and $2.66 \pm 1.25$ for the obese patients with no significant difference between them $(P>$.05). There was statistically significant difference between the groups for the presence of periodontal pockets $(P=.021)$. All the patients presented some degree of tooth wear, however, with no significant difference between the two groups $(P=.82)$. The mean saliva flow values of the surgical group and control group were $0.64 \pm 0.46 \mathrm{~mL} / \mathrm{min}$ and $0.66 \pm 0.49 \mathrm{~mL} / \mathrm{min}$, respectively. There was no significant difference in saliva flow and all oral conditions analyzed $(P>$.05).

Conclusion: The prevalence of oral diseases was similar in severely obese patients who were candidates for bariatric surgery and in patients who had been submitted to bariatric surgery. Nevertheless, there was higher prevalence of periodontal pockets in the operated group. (Eur J Dent 2012;6:191-197)
\end{abstract}

Key words: Oral health; tooth erosion; periodontal diseases; dental caries; xerostomia; obesity; bariatric surgery

1 Department of Pediatric Dentistry, Orthodontics and Public Health, Faculty of Dentistry of Bauru, University of São Paulo. Al. Octávio Pinheiro Brisolla, 9-75. Bauru-SP, BRAZIL

2 Department of Surgery and Anatomy, Faculty of Medicine of Ribeirão Preto, University of São Paulo. Avenue Bandeirantes, 3900. Ribeirão Preto, SP, BRAZIL
- Corresponding author: Dr. Silvia Helena de Carvalho Sales-Peres

Department of Pediatric Dentistry, Orthodontics and Public Health, Bauru School of Dentistry, University of São Paulo. Avenue Octávio Pinheiro Brisolla, 9-75. Bauru-SP 17012-901, BRAZIL

Tel: +55 1432358260 Fax: + 551432358260

Email: shcperesdusp.br 


\section{INTRODUCTION}

Obesity is a chronic disease recognized as a global epidemic that has spread in both developed and third world countries, ${ }^{1}$ having taken on epidemic proportions, in the U.S.A. and internationally. ${ }^{2,3}$ In the last decade, the prevalence of obesity has increased significantly in Brazil. ${ }^{4}$

Obesity causes or exacerbates many health problems, both independently and in association with other diseases. It is associated with the development of type 2 diabetes mellitus, coronary heart disease, an increased incidence of certain forms of cancer, respiratory complications lobstructive sleep apnea) and osteoarthritis of large and small joints. ${ }^{1,3}$ Obesity is related to several aspects of oral health, such as caries, periodontitis and xerostomia. ${ }^{1,5}$

Bariatric surgery is one of the therapeutic modalities considered capable of offering acceptable results, favoring rapid and effective long-term weight loss, and a reduction in the risks of morbid or co-morbidities in obesity class III and obesity class II, associated with severe co-morbidity. ${ }^{1,4}$ The success of bariatric surgery among morbidly obese patients has been recognized by the loss of excess weight, control of co-morbidities and improved postoperative quality of life. ${ }^{6}$ Bariatric surgery has become safer or more effective for achieving meaningful and sustainable weight loss. However, most of the currently performed operations result in dramatic changes in gastrointestinal anatomy, physiology, or dietary habits, which may result in gastrointestinal complications, gastritis, malnutrition, nausea and vomiting, anemia, dehydration, vitamin and mineral deficiencies (calcium, iron, folic acid, vitamin B12 and D) among others. ${ }^{7,8}$

Some studies have shown that there could be an increase in the patient's risk for dental caries, periodontal diseases, xerostomia and dentin hypersensitivity after bariatric surgery. ${ }^{8-12}$ However, the dental aspects and side-effects of bariatric surgery have not been adequately reported in the medical literature because there are few studies and the majority are case reports. ${ }^{8}$

The mouth is anatomically and physiologically an integral component of the alimentary tract and the potential negative effects of gastric surgery may manifest in the oral health area as tooth wear, dental caries, periodontal diseases, and mucosal alterations. $8,9,11-13$
The aim of this study was to compare the prevalence of dental caries, periodontal diseases and dental wear in bariatric patients and morbidly obese patients and to correlate the conditions of oral health with saliva flow.

\section{MATERIALS AND METHODS}

This study was approved by the Ethics and Research Committee of the Clinical Hospital of the Faculty of Medicine of Ribeirão Preto, University of São Paulo, Brazil. (Proc. 5855/2007). An informed consent form was signed by the patients before starting the investigation.

This research was a cross-sectional study in which the sample was composed of 102 patients with a mean age of $37.6 \pm 10.0$ years, assisted in the Faculty of Medicine Hospital Clinic of Ribeirão Preto. They were distributed into 2 groups: G1 the experimental group with 52 patients who had undergone Roux - en - Y Gastric Bypass (RYGB) surgery, and G2- the control group with 50 severely obese patients selected for bariatric surgery.

These patients were nonsmokers and only four patients had undergone periodontal treatment; however the periodontal treatment had been performed 2 years before this study was conducted.

Stimulated saliva was collected after patients' chewed paraffin wax for 5 minutes, and spat the saliva into a small cup, after which it was measured with a syringe. The saliva flow was classified as normal ( $>1.0 \mathrm{~mL} / \mathrm{min}$ ) and as hyposalivation $(<1.0 \mathrm{~mL} / \mathrm{min})^{10}$.

Clinical examinations to observe the mean number of decayed, missing or filled teeth (DMFT Index) and periodontal condition (CPI index) were performed in accordance with the World Health Organization criteria. ${ }^{14}$

The dental wear index was obtained by a modification of the TWI (Tooth Wear Index) described by Sales-Peres et al ${ }^{15}$ The criteria for examination were: (0-Normal: no evidence of wear; 1-Incipient: tooth wear in enamel; 2- Moderate: tooth wear in dentin; 3- Severe: tooth wear in pulp or secondary dentin; and 4- Restored: tooth wear leading to restoration; 9- Not assessed).

The clinical examinations were performed by a previously calibrated dental examiner.

Both descriptive and analytical approaches to data analysis were used. Data were analyzed in a personal computer using Statistica Version 7. De- 
scriptive results were analyzed as relative frequencies. The data were analyzed using the Student's-t test, Mann Whitney, Spearman's correlation and Chi-square $\left(\chi^{2}\right)$ tests to verify the association of saliva flow with tooth wear, periodontal diseases and bariatric surgery. The level of significance was $P<.05$.

\section{RESULTS}

Fifty-two operated patients and 50 obese patients were studied. There were no significant differences between the experimental group (13 men and 39 women) and the control group (14 men and 36 women) as regards gender, and mean age G1$39.6 \pm 9.6$ years and $G 2-35.55 \pm 10.2$ years, respectively.

The period that had elapsed between surgery and the survey was $16.9 \pm 20.7$ months.

There was no statistically significant difference between the two groups for the stimulated salivary flow rate median $0.65 \pm 0.47 \mathrm{~mL} / \mathrm{min}(\mathrm{G} 1$ $0.64 \pm 0.47 \mathrm{~mL} / \mathrm{min}$ and $\mathrm{G} 2-0.66 \pm 0.49 \mathrm{~mL} / \mathrm{min}$; $P>$.05). The majority of patients presented hyposalivation.

The mean DMFT index for both groups of patients was $16.08 \pm 5.72$. After bariatric surgery it was
16.11 \pm 5.19 and for the obese patients $16.06 \pm 6.29$ (Tables 1 and 4). No statistically significant difference was found for the DMFT Index ( $P=0.96)$.

There was no correlation between saliva flow and DMFT index ( $r=.06, P=.58)$.

The mean CPI was $2.86 \pm 1.08$ (G1- $3.05 \pm 0.84$ and G2- 2.66 \pm 1.25$)$. Periodontal diseases were shown to be present in $73.1 \%$ of the sextants of surgical patients and in $48.1 \%$ of those of obese patients (Table 2).

The prevalence of periodontal pockets was $88.45 \%$ in the $G 1$ and $70.00 \%$ in the $G 2(P=.02)$. There was no correlation between reduced saliva flow and CPI ( $r=-0.1, P=.34$ ) (Table 4).

As regards oral hygiene, $66 \%$ of patients reported brushing their teeth 2-3 times a day, 17\% brushed their teeth more than three times a day and only $13 \%$ reported brushing only once a day.

All patients (control and patients surgical group) had some degree of dental wear (Tables 3 and 4). No statistically significant difference was found between the groups as regards the DWI index $(P=.82)$, saliva flow and tooth wear $(r=.04$, $\mathrm{P}=.70)$.

Univariate analysis revealed that only the factor presence of periodontal pockets was significantly

Table 1. Mean DMFT index distribution according to components in the groups.

\begin{tabular}{lccc}
\hline & Decayed & Filled & Missing \\
\hline Operated & $2.28 \pm 2.37$ & $8.73 \pm 5.90$ & $5.00 \pm 5.92$ \\
Obese & $2.00 \pm 2.22$ & $9.02 \pm 6.32$ & $5.06 \pm 6.68$ \\
Total & $2.15 \pm 2.29$ & $8.87 \pm 6.08$ & $5.03 \pm 6.27$ \\
\hline
\end{tabular}

Table 2. CPI according to components in the groups.

\begin{tabular}{|c|c|c|c|c|c|c|}
\hline \multirow{2}{*}{ Group } & \multicolumn{6}{|c|}{ CPI score* } \\
\hline & 0 & 1 & 2 & 3 & 4 & $x$ \\
\hline G1 & $25.6 \%$ & $25.3 \%$ & $26.3 \%$ & $17.0 \%$ & $4.5 \%$ & $1.3 \%$ \\
\hline G2 & $38.3 \%$ & $14.7 \%$ & $15.7 \%$ & $13.0 \%$ & $4.7 \%$ & $13.6 \%$ \\
\hline
\end{tabular}

CPI score*: 0 -healthy; 1 -bleeding; 2 -calculus; 3 -pocket 3.5-5.5mm; 4 -pocket $\geqslant 6 \mathrm{~mm}$; $\mathrm{X}$-exclude sextant (less than 2 teeth)

Table 3. Dental Wear Index (DWI).

\begin{tabular}{|c|c|c|c|c|c|c|c|c|}
\hline \multirow[b]{3}{*}{ Degree } & \multicolumn{2}{|c|}{ Incisors } & \multicolumn{2}{|c|}{ Canines } & \multicolumn{2}{|c|}{ Premolars } & \multicolumn{2}{|c|}{ Molars } \\
\hline & $\mathrm{GI}$ & GII & $\mathrm{GI}$ & GII & $\mathrm{GI}$ & GII & $\mathrm{GI}$ & GII \\
\hline & $n(\%)$ & $\mathrm{n}(\%)$ & $\mathrm{n}(\%)$ & $\mathrm{n}(\%)$ & $n(\%)$ & $\mathrm{n}(\%)$ & $\mathrm{n}(\%)$ & $\mathrm{n}(\%)$ \\
\hline 0 & $15(3.6)$ & $17(4.3)$ & $5(2.4)$ & $6(3.0)$ & $9(2.2)$ & $10(2.5)$ & $13(2.1)$ & $32(5.4)$ \\
\hline 1 & $123(29.6)$ & $179(44.8)$ & $81(38.9)$ & $79(39.5)$ & $269(64.7)$ & $244(61.0)$ & $304(48.7)$ & $273(45.5)$ \\
\hline 2 & $224(53.8)$ & $150(37.5)$ & $105(50.5)$ & $88(44.0)$ & $36(8.6)$ & $59(14.8)$ & $15(2.4)$ & $26(4.3)$ \\
\hline 3 & $4(1.0)$ & $4(1.0)$ & $0(0.0)$ & $0(0.0)$ & $0(0.0)$ & $0(0.0)$ & $0(0.0)$ & $0(0.0)$ \\
\hline 4 & $0(0.0)$ & $0(0.0)$ & $2(1.0)$ & $0(0.0)$ & $0(0.0)$ & $0(0.0)$ & $0(0.0)$ & $0(0.0)$ \\
\hline 9 & $50(12.0)$ & $50(12.5)$ & $15(7.2)$ & $27(13.5)$ & $102(24.5)$ & $87(21.7)$ & $292(46.8)$ & $269(44.8)$ \\
\hline
\end{tabular}

* DWI degree: 0 - normal; 1 - incipient; 2- moderate; 3 - severe; 4- restored; 9 - could not be assessed 
associated with patients who had undergone bariatric surgery (OR=3.29; $P<$.039) (Table 4).

\section{DISCUSSION}

Nutritional factors are implicated in systemic and oral diseases, including overweight and obesity, hypertension, type 2 diabetes, cardiovascular disease, osteoporosis, dental caries, gastrointestinal disorders and most cancers, including oral cancers. ${ }^{16}$

Frequently, less aggressive therapies do not have satisfactory results in diseases caused by poor nutritional habits, such as morbid obesity, for which the most effective treatment is bariatric surgery. The growing number of bariatric procedures has increased the need to fully understand their side-effects. Bariatric surgery results in several anatomic and physiological alterations. In this study the surgery evaluated was RYGB, which is restrictive and disabsorptive bariatric surgery; however, the restrictive component has a greater clinical significance. Exclusion of the duodenum and a segment of the jejunum, in addition to inadequate ingestion of foods can cause iron, folic acid, vitamin B12, A, D, E and $\mathrm{K}$ deficiencies. ${ }^{7}$ Nausea and vomiting are commonly occur after bariatric surgery. In most cases dysfunctional eating habits, such as overeating, eating too fast, or not chewing food well may cause these complications..$^{6,7}$

The oral condition of obese patients may change after bariatric surgery, because this procedure may have side-effects that can cause alteration in the oral cavity. The relationship between dental aspects and the side-effects of bariatric surgery have not been adequately reported in the medical literature because there have been few studies and the majority of these have been case reports. ${ }^{8}$

The risk of dental caries increases if there is high frequency of sugar consumption, particularly when the sugar is retained in the mouth for long periods of time. The effect of sugar or other carbohydrates on dental caries may be reduced by fluoride application and good oral hygiene, however, a reduction in sugar intake should be the primary approach as this has many health benefits. ${ }^{16}$

In this study, the DMFT index was similar in both groups (Table 1), and although the caries index was low when compared with the epidemiological survey conducted by the Brazilian Ministry of Health. ${ }^{17}$ This survey showed that 35 to 44 yearold people had DTMF of 20.30 , in the same range as the index in the obese patients in this study, who had a reduced rate.

One study reported that there was a difference in the pattern of foods/beverages consumed after the bariatric surgery procedure. The primary difference included 5 meals/snacks daily versus 3 main meals. ${ }^{12}$ This situation increases the patient's risk of dental caries and periodontal diseases, particularly in the presence of xerostomia. ${ }^{7}$ 11

The result of this study differ from the findings of Hague et $\mathrm{al}^{11}$, who followed-up a patient who had an increase in caries activity and low salivary production after bariatric surgery (Table 4).

Table 4. Univariate analysis for patients has undergone or will undergo bariatric surgery.

\begin{tabular}{|c|c|c|c|c|c|c|}
\hline \multirow{2}{*}{ Factors } & \multicolumn{3}{|c|}{ Groups } & \multicolumn{3}{|c|}{ Univariate analysis } \\
\hline & & Bariatric & Obese & Odds ratio & $95 \% \mathrm{Cl}$ & P-Value \\
\hline \multirow{2}{*}{ Saliva flow } & Normal & 13 & 12 & \multirow{2}{*}{0.95} & \multirow{2}{*}{$0.38-2.34$} & \multirow{2}{*}{0.910} \\
\hline & Hyposalivation & 39 & 38 & & & \\
\hline \multirow{2}{*}{ Active dental caries } & No & 15 & 18 & \multirow{2}{*}{1.39} & \multirow{2}{*}{$0.60-3.19$} & \multirow{2}{*}{0.575} \\
\hline & Yes & 37 & 32 & & & \\
\hline \multirow{2}{*}{ Dental wear } & Enamel & 11 & 12 & \multirow{2}{*}{1.18} & \multirow{2}{*}{$0.45-3.10$} & \multirow{2}{*}{0.920} \\
\hline & Dentine & 40 & 38 & & & \\
\hline \multirow{2}{*}{ Dental wear - anterior teeth } & Enamel & 11 & 12 & \multirow{2}{*}{1.15} & \multirow{2}{*}{$0.45-2.91$} & \multirow{2}{*}{0.957} \\
\hline & Dentine & 40 & 38 & & & \\
\hline \multirow{2}{*}{ Dental wear - posterior teeth } & Enamel & 30 & 24 & \multirow{2}{*}{0.70} & \multirow{2}{*}{$0.32-1.54$} & \multirow{2}{*}{0.498} \\
\hline & Dentine & 22 & 25 & & & \\
\hline \multirow{2}{*}{ Periodontal diseases } & No & 1 & 5 & \multirow{2}{*}{5.67} & \multirow{2}{*}{$0.64-50.34$} & \multirow{2}{*}{0.189} \\
\hline & Yes & 51 & 45 & & & \\
\hline \multirow{2}{*}{ Periodontal pocket } & No & 6 & 15 & \multirow{2}{*}{3.29} & \multirow{2}{*}{$1.16-9.33$} & \multirow{2}{*}{$0.039 *$} \\
\hline & Yes & 46 & 35 & & & \\
\hline
\end{tabular}


Although patients submitted to bariatric surgery may be considered a group at high-risk for dental caries, because the frequency of feeding and type of food can be associated with the formation of bacterial plaque, shown to be the primary etiologic agent in dental caries and periodontal diseases, ${ }^{18}$ the DTMF index was similar in the two groups.

Several recent studies have suggested that periodontitis occurs more frequently in obese individuals than in subjects with a normal body weight. 5,19 According to Goodson ${ }^{20}$ overweight individuals appeared to have more severe periodontal diseases, when evaluated by plaque, bleeding on probing and pocket depth.

In this study no difference was found between the operated group and the obese group as regards $\mathrm{CPI}$, however there was significant difference for pocket depth $(\mathrm{P}<.05)$ (Table 4). The difference between the two groups with regard to alveolar bone loss may be associated with vitamin or mineral deficiencies, such as hypocalcemia, after bariatric surgery. ${ }^{7}$

Studies have verified that the vitamin D status may be reduced after bariatric surgery, even when supplemental calcium and vitamin D are prescribed, and bone loss frequently occurs because patients may present metabolic bone disease losteomalacia and osteoporosis). ${ }^{21,22}$ Osteoporosis may influence the bone loss in chronic periodontitis and may be a co-factor in alveolar bone loss, thus osteoporosis may be a possible risk factor for periodontal disease. ${ }^{23}$

Any acid with a $\mathrm{pH}$ below the critical $\mathrm{pH}$ of dental enamel (5.5) can dissolve the hydroxyapatite crystals in enamel. Gastric reflux may have a $\mathrm{pH}$ below 2.0 and thus the dental erosion potential increases when unstimulated salivary flow is low. 8,24 Vomiting and other gastric disorders are important risk factors for tooth wear. Although vomiting, common in bariatric patients, can be considered a risk factor for tooth wear, ${ }^{6,7}$ the dental wear index was similar for the two groups (Table 3 and 4). Heling et $\mathrm{al}^{8}$ verified that $37 \%$ of 113 patients reported greater dental hypersensitivity after bariatric surgery. Tooth wear can expose dentinal tubules and this may cause dental hypersensitivity.

Saliva has many protective functions for hard and soft tissues and contains a wide variety of antimicrobial substances that are effective against bacteria, viruses and fungi. Saliva also contains other chemoprotective factors that help to neutralize microbial damage and render environmental toxins less harmful. ${ }^{25,26}$

Obesity has been associated with reduced flow rate of stimulated whole saliva and dental caries. ${ }^{27}$ The obese patients in this study presented reduced saliva flow and according to Bond et al28 there is a reduction in stimulated saliva of patients indicated for bariatric surgery, when compared with normalweight individuals. Moreover, saliva flow has been related to inadequate water intake in patients undergoing bariatric surgery. 7,11

However, in this research a reduction in saliva flow was found in both groups. Whether obesity has a direct or indirect negative effect on salivary flow rate is unclear. Based on this question, proinflammatory cytokines derived from adipocytes and macrophages, which have accumulated in adipose tissue $^{27}$ may negatively affect the function of salivary glands due to chronic low-grade inflammation in the gland. Moreover, the authors have reported enhanced levels of proinflammatory cytokines in crevicular fluid in obese adolescents when compared with normal-weight subjects 29,30 indicating a hyperinflammatory reaction in the periodontal tissue as well.

The data of the present study showed that there was no correlation between reduced saliva flow and oral diseases, although some researchers have found a close relationship between saliva volume and the development of periodontal diseases, dental caries and tooth wear. ${ }^{12,31}$ Nevertheless, in Table 4 significant difference between $G 1$ and $G 2$ is shown for periodontal pockets, as the bariatric patients had more disease than the obese. This is in agreement with the proposal postulated by Mooder et a ${ }^{27}$ in a study conducted with adolescents.

Oral health and nutrition may have a synergistic bidirectional relationship. Oral infectious diseases and systemic diseases with oral manifestations cause an impact on the functional ability to eat, affecting diet and nutrition status. ${ }^{32}$ Poor oral health and tooth loss have negative impacts on speech functions and the ability to consume healthy foods. ${ }^{18}$ Likewise, nutrition and diet may affect the development and integrity of the oral cavity as well as the progression of oral diseases. ${ }^{32}$

Bariatric surgery is very important for health; however a multiprofessional staff is necessary in order to attend patients suitably. In this multipro- 
fessional team, a dentist would be better able to improve the oral health of these patients.

\section{CONCLUSION}

Bariatric patients showed a prevalence of oral diseases similar to that of obese patients, nevertheless there was a more prevalent condition of periodontal pockets in bariatric patients. The maintenance of healthy periodontal conditions may be considered a good strategy for morbidly obese and bariatric patients.

\section{REFERENCES}

1. Mathus-Vliegen EM, Nikkel D, Brand HS. Oral aspects of obesity. Int Dent J 2007;57:249-256.

2. Ritchie CS. Obesity and periodontal disease. Periodontol 2000 2007;44:154-163.

3. Kopelman PG. Obesity as a medical problem. Nature 2000;404:635-643.

4. Barreto Villela N, Braghrolli Neto O, Lima Curvello K, Eduarda Paneili B, Seal C, Santos D, Cruz T. Quality of life of obese patients submitted to bariatric surgery. Nutr Hosp 2004;19:367-371.

5. Saito T, Shimazaki Y, Kiyohara Y, Kato I, Kubo M, lida M, Yamashita Y. Relationship between obesity, glucose tolerance, and periodontal disease in Japanese women: the Hisayama study. J Periodontal Res 2005;40:346-353.

6. Arasaki CH, Del Grande JC, Yanagita ET, Alves AK, Oliveira DR. Incidence of regurgitation after the banded gastric bypass. Obes Surg 2005;15:1408-1417.

7. Shikora SA, Kim JJ, Tarnoff ME. Nutrition and gastrointestinal complications of bariatric surgery. Nutr Clin Pract 2007;22:29-40.

8. Heling I, Sgan-Cohen HD, Itzhaki M, Beglaibter N, Avrutis O, Gimmon Z. Dental complications following gastric restrictive bariatric surgery. Obes Surg 2006;16:1131-1134.

9. Archer-Dubon C, Esquivel-Pedraza L, Ramirez-Anguiano $J$. Palatal ulcers due to vomiting after gastric band tightening. Obes Surg 2007;17:556-558.

10. Greenway SE, Greenway FL. Root surface caries: a complication of the jejunoileal bypass. Obes Surg 2000;10:33-36.

11. Hague AL, Baechle M. Advanced caries in a patient with a history of bariatric surgery. J Dent Hyg 2008;82:22.

12. Mandel L, Da Silva K. Parotid hypertrophy and bariatric surgery: case report. J Oral Maxillofac Surg 2008;66:572574.
13. Marsicano JA, AdC Sales-Peres, NCT Peres, A Sales-Peres, PHM Alves, R Ceneviva, et al. Correlation of salivary flow with periodontal disease and tooth wear in patients undergone bariatric surgery: a pilot study. Brazilian oral research 2008;Supplement:160. (In portuguese)

14. WHO. Oral health surverys: basic methods. Geneva 1997.

15. de Carvalho Sales-Peres SH, Goya S, de Araújo JJ, SalesPeres A, Lauris JR, Buzalaf MA. Prevalence of dental wear among 12-year-old Brazilian adolescents using a modification of the tooth wear index. Public Health 2008;122:942948.

16. Palacios C, Joshipura K, Willett W. Nutrition and health: guidelines for dental practitioners. Oral Dis 2009;15:369381

17. Brasil Ministério da Saúde. Projeto SB Brasil 2003. Oral health status of the Brazilian population 2002-2003. Main results. Brasília: Departamento de Atenção Básica, Secretária de Atenção à Saúde, Ministério da Saúde, 2004. (In portuguese)

18. Persson GR. What has ageing to do with periodontal health and disease? Int Dent J 2006;56:240-249.

19. Al-Zahrani MS, Bissada NF, Borawskit EA. Obesity and periodontal disease in young, middle-aged, and older adults. J Periodontol 2003;74:610-615.

20. Goodson JM, Groppo D, Halem S, Carpino E. Is obesity an oral bacterial disease? J Dent Res 2009;88:519-523.

21. Compher CW, Badellino KO, Boullata JI. Vitamin D and the bariatric surgical patient: a review. Obes Surg 2008;18:220224.

22. De Prisco C, Levine SN. Metabolic bone disease after gastric bypass surgery for obesity. Am J Med Sci 2005;329:5761.

23. Nicopoulou-Karayianni K, Tzoutzoukos P, Mitsea A, Karayiannis $A$, Tsiklakis $K$, Jacobs $R$, Lindh C, van der Stelt P, Allen P, Graham J, Horner K, Devlin H, Pavitt S, Yuan J. Tooth loss and osteoporosis: the osteodents Study. J Clin Periodontol 2009;36:190-197.

24. Järvinen VK, Rytömaa II, Heinonen OP. Risk factors in dental erosion. J Dent Res 1991;70:942-947.

25. Gandara BK, Truelove EL. Diagnosis and management of dental erosion. J Contemp Dent Pract 1999;1:16-23.

26. Turner MD, Ship JA. Dry mouth and its effects on the oral health of elderly people. J Am Dent Assoc 2007;138 Suppl:15S-20S.

27. Modeer T, Blomberg C, Wondimu B, Lindberg TY, Marcus C. Association between obesity and periodontal risk indicators in adolescents. Int J Pediatr Obes 2011;6:e264-e270. 
28. Bond DS, Raynor HA, Vithiananthan S, Sax HC, Pohl D, Roye GD, Ryder BA, Wing RR. Differences in salivary habituation to a taste stimulus in bariatric surgery candidates and normal-weight controls. Obes Surg 2009;19:873-878.

29. Modeer T, Blomberg C, Wondimu B, Yucel-Lindberg T, Marcus C. Association between obesity and periodontal disease in adolescents. IADR MIAMI 2009; abstract no. 829.

30. Lundin M, Yucel-Lindberg T, Dahllof G, Marcus C, Modeer T. Correlation between TNFalpha in gingival crevicular fluid and body mass index in obese subjects. Acta Odontol Scand 2004;62:273-7.

31. Ito T, Komiya-Ito A, Arataki T, Furuya Y, Yajima Y, Yamada S, Okuda K, Kato T. Relationship between antimicrobial protein levels in whole saliva and periodontitis. $J$ Periodontol 2008;23:316-22.

32. Touger-Decker R, Mobley CC. Position of the American Dietetic Association: oral health and nutrition. J Am Diet Assoc 2007;107:1418-28. 